IZA DP No. 772

Search Intensity, Cost of Living and Local Labor Markets in Britain

Eleonora Patacchini

Yves Zenou

May 2003 


\title{
Search Intensity, Cost of Living and Local Labor Markets in Britain
}

\author{
Eleonora Patacchini \\ University of Southampton
}

\author{
Yves Zenou \\ University of Southampton, GAINS, \\ CEPR and IZA Bonn
}
Discussion Paper No. 772
May 2003

\author{
IZA \\ P.O. Box 7240 \\ D-53072 Bonn \\ Germany \\ Tel.: +49-228-3894-0 \\ Fax: +49-228-3894-210 \\ Email: iza@iza.org
}

\begin{abstract}
This Discussion Paper is issued within the framework of IZA's research area Welfare State and Labor Market. Any opinions expressed here are those of the author(s) and not those of the institute. Research disseminated by IZA may include views on policy, but the institute itself takes no institutional policy positions.

The Institute for the Study of Labor (IZA) in Bonn is a local and virtual international research center and a place of communication between science, politics and business. IZA is an independent, nonprofit limited liability company (Gesellschaft mit beschränkter Haftung) supported by the Deutsche Post AG. The center is associated with the University of Bonn and offers a stimulating research environment through its research networks, research support, and visitors and doctoral programs. IZA engages in (i) original and internationally competitive research in all fields of labor economics, (ii) development of policy concepts, and (iii) dissemination of research results and concepts to the interested public. The current research program deals with (1) mobility and flexibility of labor, (2) internationalization of labor markets, (3) welfare state and labor market, (4) labor markets in transition countries, (5) the future of labor, (6) evaluation of labor market policies and projects and (7) general labor economics.
\end{abstract}

IZA Discussion Papers often represent preliminary work and are circulated to encourage discussion. Citation of such a paper should account for its provisional character. A revised version may be available on the IZA website (www.iza.org) or directly from the author. 
IZA Discussion Paper No. 772

May 2003

\title{
ABSTRACT
}

\section{Search Intensity, Cost of Living and Local Labor Markets in Britain*}

\begin{abstract}
A model is considered in which optimal search intensity is a result of a tradeoff between short-run losses due to higher search costs (more interviews, commuting...) and long-run gains due to a higher chance of finding a job. We show that this optimal search intensity is higher in areas characterized by larger cost of living and/or higher labor market tightness. We then test this model using county-level data in England for the period 1991-2000. As predicted by the theoretical model, both the (county) cost of living and the (county) labor market tightness are found to have a positive and significant effect on the (county) search intensity. We also find positive spatial correlation between counties (i.e. clustering of counties with similar level of search intensity) and strong spatial spillover effects.
\end{abstract}

JEL Classification: C23, D83, J64, R1

Keywords: job matching, search intensities, dynamic panel data, GMM estimation, measurement errors, spatial correlation

Corresponding author:

Yves Zenou

Department of Economics

University of Southampton

Southampton SO17 1BJ

United Kingdom

Email: yz@soton.ac.uk

\footnotetext{
* We are grateful to Cécile Détang-Dessendre, Raymond O'Brien, Patricia Rice and Jackline Wahba for helpful comments and suggestions. We would also like to thank the ONS for information about data availability and the Group Economics, Halifax plc., for providing the data on the housing market at the county level.
} 


\section{Introduction}

There seems to be a growing awareness that some patterns of economic variables might be due to spatial rather than purely economic factors. This is particularly true in the labor market (see, for example, Topa, 2001 and Manning, 2003) and especially for job search activities since a spatial dispersion of agents creates more frictions and thus more unemployment. In his seminal contribution to search, Stigler (1961) puts geographical dispersion as one of the four immediate determinants of price ignorance. The reason is simply that distance affects various costs associated with search.

The aim of this paper is to investigate, both theoretically and empirically, the relationship between job search and space by focusing on the impact of local cost of living and local labor market tightness on search intensity.

From a theoretical point of view, few models have introduced a spatial analysis in a search-matching model. Exceptions include Seater (1979), McCormick and Sheppard (1992), Simpson (1992), Rouwendal (1998), Ortega (2000), Coulson, Laing and Wang (2001), Sato (2001), Wasmer and Zenou (2002), Smith and Zenou (2003). Contrary to these models, our focus is on search intensity and its relationship with cost of living and labor market tightness in a local labor market.

From an empirical point of view, few papers have tested spatial search models. Most of the related empirical literature (which is in fact quite small) has been focusing on the aggregation of the matching function across space and on the interaction between local matching and regional migration or commuting behavior (see in particular the survey by Petrongolo and Pissarides, 2001, and also Jackman and Savouri, 1992, Burda and Profit, 1996, Burgess and Profit, 2001). In the present paper, we analyze a different issue, namely the relationship between the county job-search intensity, on the one hand, and the county cost of living and/or the county labor market tightness, on the other.

To be more precise, we first develop a simple model in which optimal search intensity is a result of a trade off between short run losses due to higher cost of search effort (more interviews, commuting...) and long-run gains due to higher chance to find a job. We show that this optimal search intensity is higher in areas characterized by larger cost of living and/or higher labor market tightness.

We then test this model using county-level data in England for the period 1991-2000. Different econometric problems need to be taken into consideration: (i) measurement errors in search intensity and cost of living, (ii) cross-sectional 
dependence between counties, (iii) unobserved heterogeneity between counties, and $(i v)$ the fact that search intensity in a given period is affected by the one in the previous period. To take into account these four features, we estimate a spatio-temporal model specified as a typical dynamic panel data model where a spatially lagged dependent variable has been included. The advantage in using panel data models is not only the possibility to control for unobserved heterogeneity but also to allow for measurement errors in observed variables. The advantage of using spatial econometric techniques (see Anselin, 1988, and Anselin and Florax, 2002, for a review) is to control for spatial effects (spatial heterogeneity as well as spatial correlation) between counties.

As predicted by the theoretical model, both the county cost of living and the county labor market tightness are found to have a positive and significant effect on the county search intensity. We also find positive spatial correlation between counties (i.e. clustering of counties with similar level of search intensity) and strong spatial spillover effects.

The remainder of the paper is organized as follows. Section 2 presents the theoretical model and its main predictions. Section 3 describes the data while the statistical models and the estimation results are contained in Section 4. Finally, Section 5 concludes.

\section{Theoretical model}

We develop a simple model that explains how search effort decisions are made. For this purpose, we focus on the unemployed workers that are looking for a job in a given area $i$ (e.g. a county or a region).

Let us first explain the macroeconomic environment in a given area $i$. Time is continuous and workers live forever. A vacancy can be filled according to a random Poisson process. Similarly, unemployed workers can find a job according to a random Poisson process. In aggregate, these processes imply that there is a number of contacts (or matches) per unit of time between the two sides of the market in area $i$ that are determined by the following standard matching function:

$$
M_{i} \equiv M\left(s_{i} u_{i}, v_{i}\right)
$$

where $u_{i}$ and $v_{i}$ respectively denote the number of unemployed workers and vacancies in area $i$. Each unemployed worker $j=1, \ldots, u_{i}$ living in area $i$ has a search intensity equal to $s_{i j} \equiv s\left(e_{i j}\right)$, which depends on how much effort

$e_{i j}$ he/she provides in the search process. We assume that $s^{\prime}\left(e_{i j}\right)>0$ and 
$s^{\prime \prime}\left(e_{i j}\right) \leq 0$. Accordingly, $s_{i}$ represents the average intensity of search of the $u_{i}$ unemployed workers in area $i$.

As usual (Pissarides, 2000), $M($.$) is assumed to be increasing in both its$ arguments, concave and exhibits constant returns to scale. As a result, the probability of obtaining a job per unit of time for an unemployed worker $j$ in area $i$ with search intensity $s_{i j} \equiv s\left(e_{i j}\right)$ is given by:

$$
\frac{s\left(e_{i j}\right) M\left(s_{i} u_{i}, v_{i}\right)}{s_{i} u_{i}}=M\left(1, \theta_{i}\right) s\left(e_{i j}\right)
$$

where $\theta_{i}=v_{i} / s_{i} u_{i}$ is a measure of labor market tightness in search intensity units in area $i$. By using the properties of the matching function, it is easy to see that

$$
\frac{\partial M\left(1, \theta_{i}\right)}{\partial \theta_{i}}>0
$$

since more vacancies in the area increase the probability to find a job whereas more unemployed decrease this probability.

We do not determine the labor market equilibrium. Rather, we focus on the behavior of an unemployed worker that searches for a job in area $i$ and analyze how this behavior is affected by factors related to his/her residential location, such as living costs and the tightness of the local labor market.

Let us first determine the instantaneous utility function. All workers have identical preferences representable by a Cobb-Douglas utility. For the unemployed worker $j$ living in area $i$, it is given by:

$$
U\left(z_{i j}\right)=z_{i j}^{\alpha}
$$

with $0<\alpha \leq 1$ and where $z_{i j}$ is a composite good consumption. The budget constraint for the unemployed worker $j$ living in $i$ is equal to:

$$
b=C\left(e_{i j}\right)+h_{i} z_{i j}
$$

where $b$ denotes the unemployment benefit, which is not area specific, $h_{i}$, is the price of the cost of living in area $i$ (i.e. the higher this price, the more expensive is to buy consumption goods and housing in area $i)$, and $C\left(e_{i j}\right)$ is the total cost of searching for jobs. The latter encompasses the costs of buying newspapers, commuting contacting friends, phone calls, interviews... but also the opportunity of searching for a job (e.g. leisure). We assume that

$$
\frac{\partial C\left(e_{i j}\right)}{\partial e_{i j}}>0, \frac{\partial^{2} C\left(e_{i j}\right)}{\partial e_{i j}^{2}}>0
$$


i.e. more search effort implies more search costs and it is even more costly at the margin (convex function).

If one denotes the unemployed state for workers by ' 0 ', and the employed state by ' 1 ', then using (3) and (4), we can derive the following indirect utility for each unemployed worker $j$ in area $i$ :

$$
U^{0}\left(e_{i j}, h_{i}\right)=\left[\frac{b-C\left(e_{i j}\right)}{h_{i}}\right]^{\alpha}
$$

We are now equipped to write $W_{i j}^{0}$, the expected discounted lifetime utility of an unemployed worker $j$ living in area $i$ (Bellman equation). In steady-state, $W_{i j}^{0}$ is given by

$$
\begin{aligned}
r W_{i j}^{0} & =U^{0}\left(e_{i j}, h_{i}\right)+M\left(1, \theta_{i}\right) s\left(e_{i j}\right)\left(W_{i}^{1}-W_{i j}^{0}\right) \\
& =\left[\frac{b-C\left(e_{i j}\right)}{h_{i}}\right]^{\alpha}+M\left(1, \theta_{i}\right) s\left(e_{i j}\right)\left(W_{i}^{1}-W_{i j}^{0}\right)
\end{aligned}
$$

where $r \in(0,1)$ is the discount rate and $W_{i}^{1}$, the expected discounted lifetime utility of an employed worker in area $i$. Equation (7) has a standard interpretation. When a worker is unemployed today, he/she obtains an instantaneous (indirect) utility equals to $U^{0}\left(e_{i j}, h_{i}\right)$. Then, he/she can get a job with a probability $M\left(1, \theta_{i}\right) s\left(e_{i j}\right)$ and, if so, obtains an increase in utility of $W_{i}^{1}-W_{i j}^{0}$.

Let us now study the search effort decision. When making this decision, the unemployed located in an area takes as given the total unemployment level $u_{i}$ in area $i$, the total number of vacancies $v_{i}$ in area $i$ (and thus $\theta_{i}=v_{i} / s_{i} u_{i}$ the labor market tightness), the average cost of living $h_{i}$ and the expected discounted lifetime utilities $W_{i j}^{0}$ and $W_{i}^{1}$.

By maximizing (7) with respect to $e_{i j}$, we obtain ${ }^{1}$

$$
\frac{\partial W_{i j}^{0}}{\partial e_{i j}}=\frac{\partial U^{0}\left(e_{i j}^{*}, h_{i}\right)}{\partial e_{i j}}+M\left(1, \theta_{i}\right) s^{\prime}\left(e_{i j}^{*}\right)\left(W_{i}^{1}-W_{i j}^{0}\right)=0
$$

where $e_{i j}^{*}$ is the unique solution of this maximization problem and $s_{i j}^{*} \equiv s\left(e_{i j}^{*}\right)$ is the corresponding optimal search intensity.

Let us give the intuition of (8). When choosing $e_{i j}^{*}$, there is a fundamental trade-off between short-run and long-run benefits for an unemployed $j$ located in area $i$. On the one hand, increasing search effort $e_{i}$ is costly in the short run (more phone calls, more interviews, etc.) and it decreases instantaneous

\footnotetext{
${ }^{1}$ See Lemma 1 in Appendix 1 that shows that there is a unique solution to this maximization problem.
} 
utility $\left(\partial U^{0}\left(e_{i j}^{*}, h_{i}\right) / \partial e_{i j}<0\right)$, but, on the other, it increases the long-run prospects of employment $\left(M(1, \theta) s^{\prime}\left(e_{i j}^{*}\right)\left(W_{i}^{1}-W_{i j}^{0}\right)\right.$ is the marginal return of employment). We have the following result.

\section{Proposition 1}

(i) The higher the cost of living $h_{i}$ in a given area $i$, the higher the search intensity $s_{i j}^{*} \equiv s\left(e_{i j}^{*}\right)$ of an unemployed worker $j$ living in area $i$;

(ii) The higher the labor market tightness $\theta_{i}$ in area $i$, i.e. the higher the number of vacancies $v_{i}$ or the lower the unemployment level $u_{i}$ in area $i$, the higher the search intensity $s_{i j}^{*} \equiv s\left(e_{i j}^{*}\right)$ for each unemployed worker $j$ in this area.

Proof. See Appendix 1.

As stated above, when deciding the optimal level of search effort, each unemployed worker trades off the short run losses of increasing effort (higher cost of search effort $C\left(e_{i j}\right)$ and thus lower instantaneous utility $\left.U^{0}\left(e_{i j}, h_{i}\right)\right)$ with the long-run gains (higher chance to get a job and to enjoy an intertemporal utility difference between employment and unemployment). Proposition 1 analyzes the effect of living costs $h_{i}$ (short-run effect) and the one of the labor market tightness $\theta_{i}$ (long-run effect) on search effort $e_{i j}^{*}$.

When living costs increase, it becomes more costly to stay unemployed (see (4)), which reduces instantaneous utility $U^{0}\left(e_{i j}, h_{i}\right)$. As a result, the unemployed worker increases his/her search effort to raise his/her chance to obtain a job and thus be able to afford this new cost of living. The key relationship is in fact

$$
\frac{\partial^{2} U^{0}\left(e_{i j}, h_{i}\right)}{\partial e_{i j} \partial h_{i}}
$$

which is shown (see Appendix 1) to be positive and states that the effect of $e_{i j}$ on $U^{0}$ is even more negative when the living cost $h_{i}$ increases.

Furthermore, when the labor market tightness rises, it becomes easier to find a job (there are relatively more jobs available compared to the unemployed) and thus the returns to search are higher. As a result, workers put more effort in search activities.

Let us now define the optimal average search intensity $s_{i}^{*}$ of an area $i$ as

$$
s_{i}^{*}=\frac{1}{u_{i}} \sum_{j=1}^{j=u_{i}} s\left(e_{i j}^{*}\left(h_{i}, \theta_{i}\right)\right)
$$

We have: 


\section{Proposition 2}

(i) The higher the cost of living $h_{i}$ in a given area $i$, the higher the average search intensity $s_{i}^{*}$ of this area;

(ii) The higher the labor market tightness $\theta_{i}$ in an area $i$, i.e. the higher the number of vacancies $v_{i}$ or the lower the unemployment level $u_{i}$, the higher the average search intensity $s_{i}^{*}$ of this area.

\section{Proof. See Appendix 1.}

These two results are a straightforward extension of Proposition 1 since, when we aggregate the search behavior of the unemployed, both $h_{i}$ and $\theta_{i}$ do not change (i.e. $h_{i}$ and $\theta_{i}$ are respectively equal to the average cost of living and labor market tightness in area $i$ ) so that if each individual searches more when $h_{i}$ or $\theta_{i}$ increases, then, the average search intensity is also positively related to $h_{i}$ and $\theta_{i}$.

More generally, the basic message of this model is as follows. If we compare two areas (counties, cities, regions), the unemployed workers living either in the more expensive area and/or in the area with the higher labor market tightness, do search on average more.

\section{Data}

We would like now to test the predictions of the model using county-level data in England for the period 1991-2000. The key variable of the theoretical model is the average search intensity $s_{i}$. We consider as a measure of average search intensity in county $i$, hereafter the local search rate, the ratio between the number of unemployed that are actively looking for a job over the total number of unemployed in county $i .^{2}$ The other key variable in the theoretical

\footnotetext{
${ }^{2}$ In the questionnaire of our data base, the British Household Panel Survey (BHPS), people are asked their current labor force status and subsequently if they have been looking for any kind of paid job in the last four weeks. More precisely, regarding their labor force status, individuals can choose between "self-employed", "in paid employed", "unemployed", "retired", "family care", "full-time student", "long-term sick/disable", "on maternity leave", "government training scheme", "something else". In our sample, we have only included individuals that have responded "unemployed" to this question. Among them, there is surprisingly a high number who state that they have not looked for a job during the last four weeks. Our search intensity variable is thus the ratio between individuals that declare themselves as "unemployed" and "have looked actively for a job during the last four weeks" and all individuals that have responded "unemployed" to the question above. For robustness
} 
model, the average cost of living in the area $h_{i}$, is measured by a countysemidetached house price index. We are aware that the interactions between the labor market and the housing market are far more complicated (see e.g. Hughes and McCormick, 2000, Cameron and Muellbauer, 2001). However, because there is no complete set of sub-regional price indices for the UK, the main (and possibly the only) source of variation in prices within regions is differences in house prices. Furthermore, we concentrate our analysis only on young people (age 18-25) so that it is plausible to assume that, at least for the large majority of them, they are not home-owners and thus do not consider housing as an asset.

As these empirical variables are not the straightforward observable counterpart of search intensity and living costs respectively, we treat them as variables measured with errors. The discrepancies between the variables of interest and the observable ones are not supposed to be random. They might be also due to unobservable time-invariant county-specific effects such as unmeasured locational factors, and/or to county-invariant time-specific effects related for instance to some temporary effects of national policies. Very likely, the resulting measurement errors would follow a systematic rather than a random structure.

Finally, the last variable of theoretical interest is the local labor market tightness $\theta_{i}$. Fortunately, the National On-line Manpower Information Service (NOMIS) provides the exact information of the labor market tightness at the county level.

A longitudinal data set of English counties observed yearly for the period 1991-2000 has been constructed. Three different data sources have been used. The estimated local search rates have been constructed using the waves of the BHPS, that are available also on line in the ESRC Data Archive. The information about the features of the counties' housing market comes from the semidetached Halifax House Price Index. ${ }^{3}$ The remaining indicators of the local labor markets have been derived using data available from the National

check, we have used another measure of search intensity: a derived variable from the Labour Force Survey (LFS), based on the standard (ILO) definition of economic activity. The analysis with this other measure is discussed at the end of Section 4.

${ }^{3}$ The index numbers are constructed using a Laspeyres type price index methodology (similar to the one used for calculating the retail price index). The weighted average prices in each current period is compared with the weighted average price in the base period. For the Halifax House Price Index this has been chosen as 1983. For further details see http://www.hbosplc.com/view/housepriceindex/indexmethodology02.asp 
On-line Manpower Information Service (NOMIS) located at the University of Durham. Only areas with non missing values in all the variables considered are included in the sample used for estimation, in total 45 cross section units. Appendix 2 contains precise definitions for all variables. The related descriptive statistics are collected in the following table.

Table 1. Descriptive Statistics

\begin{tabular}{cccccc}
\hline Variable & Obs & Mean & Std. Dev. & Min. & Max. \\
\hline$s_{i t}$ & 450 & .6899 & .2984 & 0 & 1 \\
$\bar{s}_{i t}$ & 450 & .6762 & .2011 & 0 & 1 \\
$\theta_{i t}$ & 450 & .1707 & .1686 & .0193 & 1.0878 \\
$\bar{\theta}_{i t}$ & 450 & .1794 & .1580 & .03796 & .8052 \\
$h_{i t}$ & 450 & 63.4062 & 19.3563 & 40.648 & 188.263 \\
$\bar{h}_{i t}$ & 450 & $2.06 \mathrm{e}+09$ & $3.01 \mathrm{e}+09$ & 476 & $9.73 \mathrm{e}+09$ \\
$d_{i t}$ & 450 & 6.1868 & 8.3821 & .6 & 45.2453 \\
\hline
\end{tabular}

This table shows some interesting features. First, in our sample, the average search intensity in a county $s_{i t}$ is around $70 \%$, which means that there are on average $30 \%$ young workers entering the labor market not actively looking for a job (even if they declare themselves as unemployed). Observe that the average level of search intensity in neighboring counties $\bar{s}_{i t}$ is also around $70 \%$. Second, the labor market tightness $\theta_{i t}$ is on average equal to $17 \%$. This means that, on average, there is almost 1 vacancy for every 5 unemployed workers in a county. Here also the neighboring counties have the same average labor market tightness $\bar{\theta}_{i t}$. Finally, the features related to houses prices $\left(h_{i t}\right.$ and $\left.\bar{h}_{i t}\right)$ show a large variation of costs of living between different counties in Britain.

\section{Statistical model and estimation results}

Our empirical strategy is to test the results of Proposition 2, namely the positive relationship between $s_{i}$ and $h_{i}$ and $\theta_{i}$. As already noted above, there are measurement errors on $s_{i}$ and $h_{i}$ that need to be taken into account in the econometric specification of the empirical model. Moreover, since search intensity $s_{i}$ in county $i$ is affected by search intensities $\bar{s}_{i}$ in neighboring counties (for example individuals may live in county $i$ but search in a neighboring county if the latter offers better labor outcomes), we need to consider cross-sectional dependence in our analysis. Also, since there is unobserved heterogeneity among 
counties, we need to undertake a panel data analysis to control for fixed effects. Finally, $s_{i t}$, search intensity in county $i$ in period $t$ is also affected by $s_{i, t-1}$ the search intensity in the same county but in the previous period. As a result, a dynamic analysis must be considered.

To take into account these four features of our model, we estimate a spatiotemporal model specified as a typical dynamic panel data model where a spatially lagged dependent variable has been included. The advantage in using panel data models is not only the possibility to control for unobserved heterogeneity but also to allow for measurement errors in observed variables. The advantage of using spatial econometric techniques is to control for spatial effects (spatial heterogeneity as well as spatial correlations) between counties. Indeed, a feature often neglected in empirical studies using dynamic panel data models when the units have a spatial connotation, is the possible crosssectional dependence of the residuals. The degree of interdependence between markets in regional studies, for instance, is usually very high and studies lacking to control for it lead to unreliable estimation results. We test for and find high and positive spatial autocorrelation among levels of search intensity between counties, meaning that high values of search intensity in a location tend to be associated with high values at nearby locations. Spatial correlation may arise for a number of reasons. Instead of trying to correctly specify these channels of interdependence, we incorporate in the model a spatially lagged dependent variable and fixed effects in order to explain the spatial correlation and spatial heterogeneity respectively in the data.

The inclusion of a spatially lagged dependent variable in addition to other explanatory variables can be interpreted in two different ways. If the main empirical interest is on spatial effects, one can consider the inclusion of a spatially lagged dependent variable in addition to other explanatory variables as a way to assess the degree of spatial dependence, while controlling for the effect of these other variables. Alternatively, the inclusion of a spatially lagged dependent variable allows us to assess the significance of the other (non-spatial) variables, after the spatial dependence is controlled for. This latter strategy is the one pursued in our analysis. Our aim is to estimate the impact of the (county) cost of living and the (county) labor market tightness on the (county) search intensity once spatial effects have been filtered out. The formulation of the model is such that specification tests on the model in deviations cannot reject the hypothesis of absence of serial and spatial correlation in the residuals. Appendix 3 presents the tests for spatial correlation both on the observations 
(Table A.1) and on the residuals (Table A.2). It also contains three quantile maps (Figure 1) that illustrate the geographical distribution of the search rate, the tightness of the local labor markets and our proxy for costs of living, i.e. house prices, in Britain. It appears evident that most of the areas with high (low) levels of local search rate are the areas with high (low) levels of local labor market and cost of living.

Let us now write the econometric specification of the model that incorporates all the four features mentioned above. For that, define as $s_{i t}^{*}$ and $h_{i t}^{*}$ the true local search rate and the true local cost of living respectively, and as $s_{i t}$ and $h_{i t}$ their empirical counterparts. We assume that the process of the measurement error consists of three independent components. The first one is an individual-invariant time-specific effect, $\phi_{t}$, with mean 0 , variance $\sigma_{\phi}^{2}$ uncorrelated over time. The second is a time-invariant individual-specific effect, $\mu_{i}$ with mean 0 and variance $\sigma_{\mu}^{2}$ while the third one, $\xi_{i t}$, is a white noise component with mean 0 and variance $\sigma_{\xi}^{2}$. Let $m_{i t}$ denote a measurement error with the above considered additive structure.

In order to take into account cross-sectional dependence, we also define for county $i=1, \ldots, n$ the variable

$$
\bar{s}_{i t}^{*}=\sum_{j=1}^{n} w_{i j} s_{i t}^{*},
$$

which indicates the average value of the search rate over the counties adjacent to $i$, i.e. the counties that share a common boundary with $i$. The weights $w_{i j}$ are set equal to 0 if $i=j$ or if $i$ and $j$ are not adjacent, and are equal to a constant otherwise (defined by imposing the normalization $\sum_{j=1}^{n} w_{i j}=1$ for each $i){ }^{4}$

We are now able to write the empirical model (referred to as model 1). It is given by:

$$
\begin{aligned}
s_{i t}^{*}=\alpha s_{i, t-1}+\beta \bar{s}_{i t}^{*}+\gamma \theta_{i t}+\delta h_{i t}^{*}+\varphi d_{i t}+\eta_{i}+\varepsilon_{i t}, \\
|\alpha|<1, \quad i=1, \ldots, N ; t=2, \ldots, T \\
s_{i t}^{*}=s_{i t}+m_{i t}, \\
h_{i t}^{*}=h_{i t}+m_{i t}, \\
m_{i t}=\phi_{t}+\mu_{i}+\xi_{i t},
\end{aligned}
$$

\footnotetext{
${ }^{4}$ The $N \times N$ matrix $W=\left\{w_{i j}\right\}$ is sometimes called contiguity matrix in the spatial statistics literature. It describes the geographical arrangement of the spatial units.
} 
where $\theta_{i t}$ denotes the local labor market tightness in county $i$ at time $t, d_{i t}$ is the population density in county $i$ at time $t, \eta_{i}$ is a county-specific constant capturing also spatial effects due for instance to different county size (spatial heterogeneity) and $\varepsilon_{i t}$ is a white noise disturbance term.

Observe that the empirical model does not include any measure of the average human capital characteristics of the different counties, nor other features of the local structure of the population. The reason is that we assume that the impact of these characteristics on the local search rate in each county is captured through the inclusion of (time) lagged values of the local search rate.

The first order space-time autoregressive model 1 (equation (11)) is estimated using an instrumental variables approach within a Generalized Method of Moments (GMM) estimation procedure. After controlling for spatial dependence in the data by choosing an appropriate order in the spatial process, the literature on dynamic panel data models can be used. The estimation procedure developed is similar to the one proposed by Arellano and Bond (1991). Distributional assumptions are not needed. Measurement errors in observed variables are taken into account by using sufficiently lagged variables as instruments. Technical details on the estimation procedure of the resulting dynamic panel data model, which presents some non-standard properties due to the error structure, are described in Appendix 4.

The estimation results of (11) are contained in the first two columns of Table 2. ${ }^{5}$ The first column reports the results for the Arellano and Bond (1991) GMM estimator, which consists in taking first differences over time to get rid of the unit specific error terms and in using appropriate instruments for the lagged (spatially and temporally) dependent variable and for all the others endogenous variables. Both living cost and the tightness of the local labour markets are treated as potentially endogenous variables. Therefore, the instrumental set contains observations on the tightness of the local labour markets dated $(t-2)$ and earlier and observations on local cost of living, local search rate and search rate in neighbor counties dated $(t-3)$ and earlier. Note that the use of three-times periods lagged variables instead of the standard two-times periods lagged ones for the variables indicating the cost of living and the search rate is due to the additional endogeneity problem caused by the

\footnotetext{
${ }^{5}$ All the reported results are two step GMM estimation, obtained using the DPD98 package for Ox. One step results are not considered because we deal only with 45 cross section units and the estimated standard errors are severely downward biased in small sample. Windmeijer (2000) derived a small-sample correction which is implemented in the two step estimation routine.
} 
presumed presence of measurement errors. Under the specified assumptions for the composed error structure, valid instruments are only obtained by using variables that are at least three-times periods lagged, as shown in Appendix 3. We do not use the whole history of the variables as instruments. We truncated the history after $(t-5)$. Although the number of overidentifying restrictions is still rather large compared to the sample size, we do not find any evidence of a possible overfitting bias. Table 2 also reports the Sargan tests of the overidentifying restrictions (Sargan, 1958; Hansen, 1982) implied by the instrument matrix and the tests for autocorrelation. The Sargan test is asymptotically distributed as $\chi^{2}$ under the null of instrument validity, with degrees of freedom reported in parentheses. $A R(1)$ and $A R(2)$ are tests for first-order and second-order serial correlation in the first-differenced residuals asymptotically distributed as $N(0,1)$ under the null of no serial correlation (Arellano and Bond, 1991). The consistency of the GMM estimators requires the absence of serial correlation in the original error term. In turn, this requires negative first-order, but no second-order correlation in the differenced error term. No evidence of misspecification is revealed.

Let us now interpret the results of the first column of Table 2 (GMM-DIF). As predicted by the theoretical model, both the (local) cost of living $h$ and the (local) labor market tightness $\theta$ are found to have a positive and significant effect on unemployed search intensity. To be more precise, a $1 \%$ increase in the cost of living in a county implies a $14 \%$ increase in average search intensity in the county. ${ }^{6}$ Furthermore, the average level of labor market tightness $\theta$ increases search effort by $20 \%{ }^{7}$

Although a spatially lagged dependent variable $(\bar{s})$ has been included in the model only to control for spatial correlation, and it is not a target variable, the estimated coefficient is significant, it presents an interesting positive sign and

\footnotetext{
${ }^{6}$ Observe that, because the proxy used for (local) living costs is (local) house prices and not an index of all the consumption goods, the effect of the cost of living on search intensity should be smaller. However, since housing constitutes an important part of the household expenses, the difference should not be very big.

${ }^{7}$ To be sure that our estimates are not affected by reverse causality between local search rate and local houses prices, model 1 has also been estimated instrumenting the cost of living by taking the historical prices. The Halifax price index at the beginning of 1988, the first period of the available series, has been used as instruments. The reasoning underlying is that today's house prices are correlated with the historical prices but probably no determinants of today's local search rate in a county are affected by local house prices in 1988 . The qualitative estimation results remain qualitatively unchanged. Therefore they are not reported here, but are available upon request.
} 
it is of a large magnitude. Indeed, counties where people have an active search behavior in the labor market appear to be clustered together (because of the positive spatial correlation that we found) and are also strongly interrelated. In other words, counties that have high search intensity tend to be geographical adjacent to counties are also characterized by high search intensity, implying important spatial spillover effects.

We have added in the regression analysis the population density $d$ to control for agglomeration effects. The coefficient on population density is not significantly different from zero.

[Insert Table 2 about here]

Let us now focus on the second column of Table 2. A more reliable and precise GMM estimator can be obtained by combining this set of moment conditions relating to the equations in levels with a set of moment conditions relating to the equations in first differences. However, the validity of the extra instruments for the equation in levels, meaning that they are uncorrelated with the area-specific effects, has to be tested. Full details and references are given in Appendix 3. In our analysis, we find that the extended set of moment restrictions is not rejected by the Sargan test of over-identifying restrictions. No evidence of serial correlation in the original errors is provided.

It is easy to see that the estimated values of the coefficients of the second column of Table 2 (GMM-SYS) are very similar to the ones of the first column (GMM-DIF). This is consistent with the underlying econometric theory since a dramatic improvement in performance of the combined GMM (GMM-SYS) compared to the usual first-differences GMM (GMM-DIF) usually occurs with very short sample periods and persistent series or if the variance of the county effects $\eta_{i}$ exceeds the variance of the residuals $\varepsilon_{i t}$. As these features are not present in our case (moderate number of points in time, small autoregressive parameter and $\left.\operatorname{Var}\left(\eta_{i}\right)<\operatorname{Var}\left(\varepsilon_{i t}\right)\right)$, the similarity in the figures of the two columns is not unexpected. The gain in precision resulting in smaller standard errors in the second column are due to the use of valid additional moment restrictions. The important implication for our analysis is that the strong and positive association between average search intensity, costs of living and labor market tightness appears to be confirmed and reliable. ${ }^{8}$

\footnotetext{
${ }^{8}$ In order to test the sensitivity of the results to the measure of the tightness of the (local) labor market $\theta$, we have also estimated an alternative specification of model (11) using a measure of $\theta$ based on flows rather than stocks, i.e. $\theta$ is measured by the yearly ratio between
} 
Because the coefficient of the search rate in neighboring counties is positive and significant, we investigate further the presence of spatial effects using the following formulation (referred to as model 2):

$$
\begin{gathered}
s_{i t}^{*}=\alpha s_{i, t-1}+\beta \bar{s}_{i t}^{*}+\gamma \theta_{i t}+\gamma_{1} \bar{\theta}_{i t}+\delta h_{i t}^{*}+\delta_{1} \bar{h}_{i t}^{*}+\varphi d_{i t}+\eta_{i}+\varepsilon_{i t}, \\
|\alpha|<1, \quad i=1, \ldots, N ; T=2, \ldots, T
\end{gathered}
$$

where the variables that were already in model 1 (equation (11)) are defined in exactly the same way and where the spatial averages $\bar{\theta}_{i t}$ and $\bar{h}_{i t}^{*}$ are defined in a similar way as in (10).

The last two columns of Table 2 contain the estimation results for model 2 . Even though not in the theoretical model, these results have been reported in order to confirm the strong spatial interdependence between local labor markets in Britain, as suggested by the preliminary tests for spatial correlation. The diagnostic tests (AR(1), AR(2), Sargan) suggest that the model is well specified, the instruments appear to be valid and the errors are white noise. All the coefficients show the expected sign suggesting that the theoretical predictions are confirmed, but, once the values of a variable in a neighboring location are introduced into the model, the coefficients of the key variables, $h$ and $\theta$, retain their positive signs but lose their significance. It indicates possible multicollinearity between local and neighboring values, suggesting a high degree of correlation between them and thus strong spatial spillovers.

Finally, one may object that our measure of unemployment in the definition of $s_{i t}$ from the BHPS (see Appendix 2) is based on self-reporting behavior (see our discussion in footnote 2). For robustness check, we estimate the empirical model 1 (equation (11)) using data from the Labor Force Survey (LFS) ${ }^{9}$ aggregated yearly at county level for a comparable time period (1992-2000). In this data set, unemployment is now defined according to the standard ILO definition. Our dependent variable is not anymore $s_{i t}^{*}$ but $n a_{i t}^{*}$, the inactivity rate in county $i$ at time $t$ (for a precise definition of our measure of inactivity rate, $n a_{i t}$, see Appendix 2). On the right hand side of equation (11), $s_{i, t-1}$ and $\bar{s}_{i t}^{*}$ have also been replaced by $n a_{i, t-1}$ and $\bar{n}_{i t}^{*}$. We believe that the inactivity rate is an inverse measure of the search intensity rate since when it has a high value in a county it implies that individuals are not actively searching for a

monthly notified vacancies and unemployed on-flows. The estimation results obtained are similar to the ones of the first two columns of Table 2 and are thus not reported here.

${ }^{9}$ All the LFS data are also available on line in the ESRC data archive. Observe that another advantage of using the LFS compared to the BHPS is that the sub-sample relevant for our analysis has a larger number of observations. 
job. As a result, we expect to obtain reverse signs for $h$ and $\theta$ since counties with large cost of living and/or high labor market tightness should have lower inactivity rate. Our results (that are not reported here but are available upon request) show indeed the estimated coefficients of the (local) cost of living and the (local) labor market tightness are now negative and significant for both variables. ${ }^{10}$

\section{Conclusion}

In this paper, we have developed a model that shows why areas with large cost of living and/or high labor market tightness are characterized by high levels of search intensity. The intuition is quite simple. The search decision is a trade off between today marginal cost (more search effort implies more commuting, more interviews, more phone calls...) and tomorrow marginal benefit (more search effort yields higher chance to find a job). So, when the cost of living of an area increases, it raises the marginal cost of searching but does not affect the marginal benefit. As a result, workers increase their search effort to compensate for this instantaneous loss of utility $\left(\partial^{2} U^{0}\left(e_{i j}, h_{i}\right) / \partial e_{i j} \partial h_{i}>0\right)$. Similarly, when the tightness of the labor market of an area increases, it raises the marginal benefit of searching but does not affect the marginal cost. Thus, workers increase their search effort because their chance to obtain a job is higher $\left(\partial M\left(1, \theta_{i}\right) / \partial \theta_{i}>0\right)$.

We then test the predictions of this model using county-level data in England for the period 1991-2000. We estimate a spatio-temporal model specified as a typical dynamic panel data model where a spatially lagged dependent variable has been included. As predicted by the theoretical model, both the county cost of living and the county labor market tightness are found to have a positive and significant effect on the county search intensity. We also find positive spatial correlation between counties (i.e. clustering of counties with similar level of search intensity) and strong spatial spillover effects. This suggests that an interesting direction for future research is to examine in more details these spatial spillovers and in particular their impact on job-search behaviors in local labor markets.

\footnotetext{
${ }^{10}$ All the empirical analysis presented in the paper has also been performed excluding London. The estimation results are qualitatively unchanged and thus not reported here.
} 


\section{References}

[1] Arellano, M. and S. Bond (1991), "Some test of specification for panel data: Monte Carlo evidence and an application to employment equations", Review of Economic Studies, 58, 277-297.

[2] Arellano, M. and O. Bover (1995), "Another look at the instrumental variable estimation of error-components models", Journal of Econometrics, 68, 29-51.

[3] Anselin, L. (1988), Spatial Econometrics: Methods and Models, Dordrecht: Kluwer Academic Publishers.

[4] Anselin, L. (2001), "Spatial econometrics", in Baltagi, B. (eds), Companion to Econometrics, Oxford: Basil Blackwell.

[5] Anselin, L. and R. Florax (2002), Advances in Spatial Econometrics, Heildeberg: Springer-Verlag.

[6] Blundell, R. and S. Bond (1995), "Initial conditions and moment restrictions in dynamic panel data models", Journal of Econometrics, 87,115143.

[7] Biorn, E. (2000), "Panel data with measurement errors: Instrumental variables and GMM procedures combining levels and differences", Econometric Review, 19, 391-424.

[8] Burda, M. and S. Profit (1996), "Matching across space: Evidence on mobility in the Czech Republic", Labour Economics, 3, 255-278.

[9] Burgess, S. and S. Profit (2001), "Externalities in the matching of workers and firms in Britain", Centre for Economic Performance Discussion Paper 490, London School of Economics.

[10] Cameron, G. and J. Muellbauer (2001), "Earnings, unemployment and housing in Britain", Journal of Applied Econometrics, 16, 203-220.

[11] Cliff, A.D. and J.K. Ord (1973), Spatial Autocorrelation, London: Pion Limited.

[12] Cliff AD. and J.K. Ord. (1981), Spatial Processes: Models and Applications, London: Pion 
[13] Coulson, E., Laing, D. and P. Wang (2001), "Spatial mismatch in search equilibrium", Journal of Labor Economics, 19, 949-972.

[14] Hansen, L. (1982), "Large sample properties of generalized methods of moments estimators", Econometrica, 50, 1029-1054.

[15] Hughes, G. and B. McCormick (2000), "Housing policy and labour market performance", Report for DETR, unpublished manuscript, University of Southampton.

[16] Jackman, R.and S. Savouri (1992), "Regional migration in Britain: An analysis of gross flows using NHS central register data", Economic Journal, 102, 1433-1450.

[17] Manning, A. (2003), "The real thin theory: Monopsony in modern labour markets", Labour Economics, forthcoming.

[18] McCormick, B. and S. Sheppard (1992), "A model of regional contraction and unemployment", Economic Journal, 102, 366-377.

[19] Ortega, J. (2000), "Pareto-improving immigration in an economy with equilibrium unemployment", Economic Journal, 110, 92-112.

[20] Petrongolo, B. and C.A. Pissarides (2001), "Looking into the black box: a survey of the matching function", Journal of Econmic Literature, 39, 390-431.

[21] Pissarides, C.A. (2000), Equilibrium Unemployment Theory, Cambridge (MA.): The MIT Press.

[22] Rouwendal, J. (1998), "Search theory, spatial labor markets, and commuting", Journal of Urban Economics, 43, 1-22.

[23] Sargan, J. D. (1958), "The estimation of economic relationships using instrumental variables", Econometrica, 26, 393-415.

[24] Sato, Y. (2001), "Labor heterogeneity in an urban labor market", Journal of Urban Economics, 50, 313-337.

[25] Seater, J. (1979), "Job search and vacancy contacts", American Economic Review, 69, 411-419. 
[26] Simpson, W. (1992), Urban Structure and the labor Market. Worker Mobility, Commuting, and Underemployment in Cities, Oxford: Clarendon Press.

[27] Smith, T.E. and Y. Zenou (2003), "Spatial mismatch, search effort and urban spatial structure", Journal of Urban Economics, forthcoming.

[28] Stigler, G.J. (1961), "The Economics of information", Journal of Political Economy, 70, 94-104.

[29] Topa, G. (2001), "Social interactions, local spillovers and unemployment", Review of Economic Studies, 68, 261-295.

[30] Upton, G.J. and B. Fingleton (1985), Spatial Data Analysis by Example, New York: Wiley.

[31] Wasmer, E. and Y. Zenou (2002), "Does city structure affect job search and welfare?", Journal of Urban Economics, 51, 515-541.

[32] Windmeijer, F. (2000), "A finite sample correction for the variance of linear two step estimators", Working Paper 00/19, The Institute of Fiscal Studies, London. 


\section{Appendix 1: Proofs of propositions}

\section{$\underline{\text { Proof of Proposition } 1}$}

Before proving this proposition, let us state the following Lemma.

Lemma 1 There is a unique solution $e_{i j}^{*}\left(h_{i}, \theta_{i}\right)$ to the first order condition (8).

Proof. It is easy to verify that the second order condition is given by:

$$
S O C \equiv \frac{\partial^{2} U^{0}\left(e_{i j}, h_{i}\right)}{\partial e_{i j}^{2}}+M\left(1, \theta_{i}\right) s^{\prime \prime}\left(e_{i j}^{*}\right)\left(W_{i}^{1}-W_{i j}^{0}\right)
$$

Now, we have

$$
\frac{\partial U^{0}\left(e_{i j}, h_{i}\right)}{\partial e_{i j}}=-\alpha\left[b-C\left(e_{i j}\right)\right]^{\alpha-1} \frac{\partial C\left(e_{i j}\right)}{\partial e_{i j}} h_{i}^{-\alpha}<0
$$

and

$$
\begin{aligned}
\frac{\partial^{2} U^{0}\left(e_{i j}, h_{i}\right)}{\partial e_{i j}^{2}}= & \alpha(\alpha-1) h_{i}^{-\alpha}\left[b-C\left(e_{i j}\right)\right]^{\alpha-2}\left[\frac{\partial C\left(e_{i j}\right)}{\partial e_{i j}}\right]^{2} \\
& -\alpha h_{i}^{-\alpha}\left[b-C\left(e_{i j}\right)\right]^{\alpha-1} \frac{\partial^{2} C\left(e_{i j}\right)}{\partial e_{i j}^{2}}
\end{aligned}
$$

which, using (5), is obviously negative since $\alpha \leq 1$. As a result

$$
S O C \equiv \frac{\partial^{2} U^{0}\left(e_{i j}, h_{i}\right)}{\partial e_{i j}^{2}}+M\left(1, \theta_{i}\right) s^{\prime \prime}\left(e_{i j}\right)\left(W_{i}^{1}-W_{i j}^{0}\right)<0
$$

since $s^{\prime \prime}\left(e_{i j}\right)<0$. There is thus a unique solution $e_{i j}^{*}\left(h_{i}, \theta_{i}\right)$ to the worker's maximization problem.

Let us now prove Proposition 1.

Let us first prove $(i)$. By totally differentiating (8), we easily obtain:

$$
\frac{\partial e_{i j}^{*}}{\partial h_{i}}=-\frac{1}{S O C} \frac{\partial^{2} U^{0}\left(e_{i j}^{*}, h_{i}\right)}{\partial e_{i j} \partial h_{i}}
$$

where $S O C$, the second order condition, is strictly negative by Lemma 1 . We have

$$
\frac{\partial^{2} U^{0}\left(e_{i j}^{*}, h_{i}\right)}{\partial e_{i j} \partial h_{i}}=\alpha^{2}\left[b-C\left(e_{i j}\right)\right]^{\alpha-1} \frac{\partial C\left(e_{i j}\right)}{\partial e_{i j}} h_{i}^{-\alpha-1}>0
$$


As a result,

$$
\frac{\partial e_{i j}^{*}}{\partial h_{i}}=-\frac{1}{S O C} \frac{\partial^{2} U^{0}\left(e_{i j}^{*}, h_{i}\right)}{\partial e_{i j} \partial h_{i}}>0
$$

which implies that

$$
\frac{\partial s_{i j}^{*}}{\partial h_{i}}=\frac{\partial s_{i j}^{*}}{\partial e_{i j}^{*}} \frac{\partial e_{i j}^{*}}{\partial h_{i}}>0
$$

Let us now prove (ii). By totally differentiating (8) and by using (2), we easily obtain:

$$
\frac{\partial e_{i j}^{*}}{\partial \theta_{i}}=-\frac{1}{S O C} \frac{\partial M\left(1, \theta_{i}\right)}{\partial \theta_{i}} s^{\prime}\left(e_{i j}^{*}\right)\left(W_{i}^{1}-W_{i j}^{0}\right)>0
$$

This implies that

$$
\frac{\partial s_{i j}^{*}}{\partial \theta_{i}}=\frac{\partial s_{i j}^{*}}{\partial e_{i j}^{*}} \frac{\partial e_{i j}^{*}}{\partial \theta_{i}}>0
$$

\section{Proof of Proposition 2}

For $(i)$, we have:

$$
\frac{\partial s_{i}^{*}}{\partial h_{i}}=\frac{1}{u_{i}}\left[\frac{\partial\left(\sum_{j=1}^{j=u_{i}} s\left(e_{i j}^{*}\left(h_{i}, \theta_{i}\right)\right)\right)}{\partial h_{i}}\right]=\frac{1}{u_{i}}\left[\sum_{j=1}^{j=u_{i}} \frac{\partial\left(s\left(e_{i j}^{*}\left(h_{i}, \theta_{i}\right)\right)\right)}{\partial h_{i}}\right]>0
$$

since by definition $s_{i j}^{*}=s\left(e_{i j}^{*}\left(h_{i}, \theta_{i}\right)\right)$.

For $(i i)$, if we consider $\theta_{i}$ as one variable (because of the assumption of constant returns to scale of the matching function), then

$$
\frac{\partial s_{i}^{*}}{\partial \theta_{i}}=\frac{1}{u_{i}}\left[\frac{\partial\left(\sum_{j=1}^{j=u_{i}} s\left(e_{i j}^{*}\left(h_{i}, \theta_{i}\right)\right)\right)}{\partial \theta_{i}}\right]=\frac{1}{u_{i}}\left[\sum_{j=1}^{j=u_{i}} \frac{\partial\left(s\left(e_{i j}^{*}\left(h_{i}, \theta_{i}\right)\right)\right)}{\partial \theta_{i}}\right]>0
$$

Now, since the average $s_{i}^{*}$ is affected by $u_{i}$, let us do the analysis for $v_{i}$ and $u_{i}$ separately. For $v_{i}$, we have:

$$
\frac{\partial s_{i}^{*}}{\partial v_{i}}=\frac{1}{u_{i}}\left[\frac{\partial\left(\sum_{j=1}^{j=u_{i}} s\left(e_{i j}^{*}\left(h_{i}, \theta_{i}\right)\right)\right)}{\partial v_{i}}\right]=\frac{1}{u_{i}}\left[\sum_{j=1}^{j=u_{i}} \frac{\partial\left(s\left(e_{i j}^{*}\left(h_{i}, \theta_{i}\right)\right)\right)}{\partial v_{i}}\right]>0
$$


whereas for $u_{i}$, we obtain:

$$
\frac{\partial s_{i}^{*}}{\partial u_{i}}=\frac{\partial\left(\frac{1}{u_{i}} \sum_{j=1}^{j=u_{i}} s\left(e_{i j}^{*}\left(h_{i}, \theta_{i}\right)\right)\right)}{\partial u_{i}}=-\frac{1}{u_{i}^{2}} \sum_{j=1}^{j=u_{i}} s\left(e_{i j}^{*}\left(h_{i}, \theta_{i}\right)\right)+\frac{1}{u_{i}}\left[\sum_{j=1}^{j=u_{i}} \frac{\partial\left(s\left(e_{i j}^{*}\left(h_{i}, \theta_{i}\right)\right)\right)}{\partial u_{i}}\right]<0
$$

\section{Appendix 2: Description of variables}

$s_{i t}$ : Ratio between unemployed persons aged between 18 and 25 actively searching for a job and unemployed between 18 and 25 in county $i$ at time $t$. An active job seeker is a person who was neither "at work" nor "with a job but not at work" during the week before the reference day and that has taken active steps to find a work (applied directly to employer, replied to adverts, used jobcentre or employment agency, asked friends or contacts, taken steps to start own business). Source: BHPS, wave 1-10, 1991-2000.

$\bar{s}_{i t}$ : Average $s_{i t}$ in the counties that share a boundary with county $i$ at time $t$. Source: BHPS, wave 1-10, 1991-2000.

$\theta_{i t}$ : Ratio between unfilled vacancies and unemployed in county $i$ at time $t$. Source: NOMIS.

$\bar{\theta}_{i t}$ : Average $\theta_{i t}$ in the counties that share a boundary with county $i$ at time $t$. Source: NOMIS.

$h_{i t}$ : Average yearly semidetached Halifax price index for county $i$ at time $t$. The index is the arithmetic average prices of houses on which an offer of mortgage has been granted, constructed on a quarterly base. The yearly average has been calculated on the available quarterly values. The figures of the Isle of Wight are not available for the years 1991-1997 and 2000. The county has been cancelled from our sample. Source: Group Economics, Halifax plc.

$\bar{h}_{i t}$ : Average $h_{i t}$ in the counties that share a boundary with county $i$ at time $t$. Source: Group Economics, Halifax plc

$d_{i t}$ : Ratio of residents over squared hectometers in county $i$ at time $t$. Variable taken from the 1991 Census database and subsequently updated using the Midyear Population Estimates. Source: NOMIS. Years: 1992-2000.

$n a_{i t}$ : Ratio between inactive persons (between 18 and 25 years old) -not seeking job but willing to work- and inactive and unemployed persons (between 18 and 25 years old) in county $i$ at time t. Source: LFS-INECA variable. It is a derived variable which classifies the individual economic activity according to the ILO standard definitions. 


\section{Appendix 3: Measures of global spatial autocorrelation}

When the variable under investigation is measured on a continuous scale, the measurement of global spatial autocorrelation is usually based on Moran's $I$ and Geary's c statistics (Cliff and Ord, 1973, 1981; Upton and Fingleton 1985). They measure the deviation from spatial randomness, or the lack of any pattern. Under this assumption, any grouping of high or low values in a particular area would be totally spurious. The existence of a spatial structure is detected by the presence of spatial correlation, that can be defined as the coincidence of value similarity with locational similarity (Anselin, 2001). There is positive spatial autocorrelation when high or low values of a random variable tend to cluster in space (spatial clustering) and there is negative spatial autocorrelation when geographical areas tend to be surrounded by neighbors with very dissimilar values (spatial outliers). Moran's $I$ is defined as

$$
I=\frac{n}{S_{0}} \frac{\sum_{i=1}^{n} \sum_{j=1}^{n} w_{i j} z_{i} z_{j}}{\sum_{i=1}^{n} z_{i}^{2}}
$$

where $n$ is the number of observations, $z_{i}$ are variables in deviations from the mean, $w_{i j}$ are elements of a spatial weights matrix, that indicate the way area $i$ is spatially connected to area $j$, and $S_{0}$ is a scaling factor equal to the sum of all the elements in the weight matrix.

Geary's $c$ is defined as

$$
c=\frac{n-1}{2 S_{0}} \frac{\sum_{i=1}^{n} \sum_{j=1}^{n} w_{i j}\left(x_{i}-x_{j}\right)^{2}}{\sum_{i=1}^{n} z_{i}^{2}}
$$

where the $x_{i} s$ are the original variables and the other notation is as above (formula 14).

Moran's $I$ is a cross product coefficient scaled to be less than one. Positive values for Moran's I indicate positive spatial correlation, while negative values indicate negative spatial correlation. In contrast, Geary's $c$ coefficient is based on squared deviations. Values of Geary's $c$ less than one indicate positive spatial correlation, while values larger than one suggest negative spatial correlation.

Table A.1 reports Moran's $I$ statistic and Geary's $c$ statistic of the search rate for each year of the period 1991-2000, for the counties in Britain (column 
two). Inference is based on a conventional normality approach. The third column in Table A.1 reports the standardized $z$-value for $I$ and $c$, computed by subtracting the expected value and dividing by the standard deviation assuming an approximation of the (asymptotic) distributions of $I$ and $c$ by the normal distribution. The associated significance level, $p_{1}$, is reported in column four. Table A.1 shows clearly that (local) search rates are positively spatially autocorrelated in every year. Both $I$ and $c$ statistics are highly significant (the indicators of significance, $p_{1}$, are always almost 0 ) and display clear evidence of positive spatial autocorrelation of the variable under analysis (positive value for the standardized Moran's I, $z(I)$, and negative values for the standardized Geary's $c$ statistic, $z(c))$. Table A.2 reports Moran's $I$ statistic and Geary's $c$ statistic calculated on the residuals of model 1. It has the same structure of Table A.1. It shows that both $I$ and $c$ statistics are no longer significant (at $5 \%$ significance level) in any year confirming that the spatial dependence has been adequately dealt with by incorporating the spatial lag term. 
Table A1: Measures of Global Spatial Correlation Search Rate

\begin{tabular}{clll}
\hline \hline \multicolumn{5}{c}{ Moran's $I$ test for spatial autocorrelation } \\
\hline \hline Year & $I$ & $z(I)$ & $p_{1}$ \\
\hline 1991 & 0.1963 & 8.9542 & 0.0000 \\
1992 & 0.2396 & 10.8744 & 0.0000 \\
1993 & 0.2235 & 6.6758 & 0.0000 \\
1994 & 0.2678 & 7.9698 & 0.0000 \\
1995 & 0.1309 & 6.1089 & 0.0000 \\
1996 & 0.1510 & 6.9777 & 0.0000 \\
1997 & 0.1949 & 8.9158 & 0.0000 \\
1998 & 0.2290 & 10.4729 & 0.0000 \\
1999 & 0.1353 & 6.2787 & 0.0000 \\
2000 & 0.1447 & 6.6827 & 0.0000 \\
\hline \hline
\end{tabular}

Geary's $c$ test for spatial autocorrelation

\begin{tabular}{llll} 
Year & $c$ & $z(c)$ & $p_{1}$ \\
\hline 1991 & 0.7571 & -7.8190 & 0.0000 \\
1992 & 0.7208 & -8.9887 & 0.0000 \\
1993 & 0.7188 & -6.2914 & 0.0000 \\
1994 & 0.6926 & -6.8789 & 0.0000 \\
1995 & 0.8312 & -5.4334 & 0.0000 \\
1996 & 0.7958 & -6.5707 & 0.0000 \\
1997 & 0.7490 & -8.0815 & 0.0000 \\
1998 & 0.7263 & -8.8105 & 0.0000 \\
1999 & 0.8435 & -5.0361 & 0.0000 \\
2000 & 0.8124 & -6.0389 & 0.0000 \\
\hline
\end{tabular}


Table A2: Measures of Global Spatial Correlation Residuals from model 1

\begin{tabular}{clll}
\hline \hline \multicolumn{5}{c}{ Moran's $I$ test for spatial autocorrelation } \\
\hline \hline Year & $I$ & $z(I)$ & $p_{1}$ \\
\hline 1991 & 0.0289 & 1.0755 & 0.2821 \\
1992 & 0.0432 & 1.4871 & 0.1370 \\
1993 & 0.0059 & 0.4136 & 0.6792 \\
1994 & -0.0164 & -0.229 & 0.8188 \\
1995 & -0.0051 & 0.0961 & 0.9234 \\
1996 & -0.0397 & -0.8989 & 0.3687 \\
1997 & -0.0583 & -1.4352 & 0.1512 \\
1998 & 0.1517 & 0.9487 & 0.3428 \\
1999 & -0.0019 & 0.1891 & 0.8500 \\
2000 & 0.0485 & 0.5480 & 0.5837 \\
\hline \hline
\end{tabular}

Geary's $c$ test for spatial autocorrelation

\begin{tabular}{lllll}
\hline \hline Year & $c$ & $z(c)$ & $p_{1}$ \\
\cline { 2 - 5 } 1991 & 0.9303 & -1.5596 & 0.1188 \\
1992 & 0.9618 & -0.8555 & 0.3922 \\
1993 & 0.9264 & -1.6473 & 0.0995 \\
1994 & 1.0882 & 1.1951 & 0.2320 \\
1995 & 1.0787 & 1.1025 & 0.2702 \\
1996 & 1.0866 & 1.1899 & 0.2341 \\
1997 & 0.9181 & -1.6557 & 0.0974 \\
1998 & 0.9507 & -0.9512 & 0.3415 \\
1999 & 0.9988 & -0.8205 & 0.4119 \\
2000 & 0.9771 & -0.8904 & 0.3732 \\
\hline
\end{tabular}


The remainder of this Appendix shows in Figure 1 the geographical distribution of the search rate (first panel), the tightness of the local labor markets (panel on the left) and our proxy for costs of living, i.e. house prices, (panel on the right) in Britain at the NUTS3 level of spatial disaggregation for the year 2000. Extremely similar maps can be obtained for all the other years considered in the analysis. Therefore they are not reported here. ${ }^{11}$

\footnotetext{
${ }^{11}$ All computations and maps are carried out using Spacestat 1.90 and Arcview 3.2.
} 

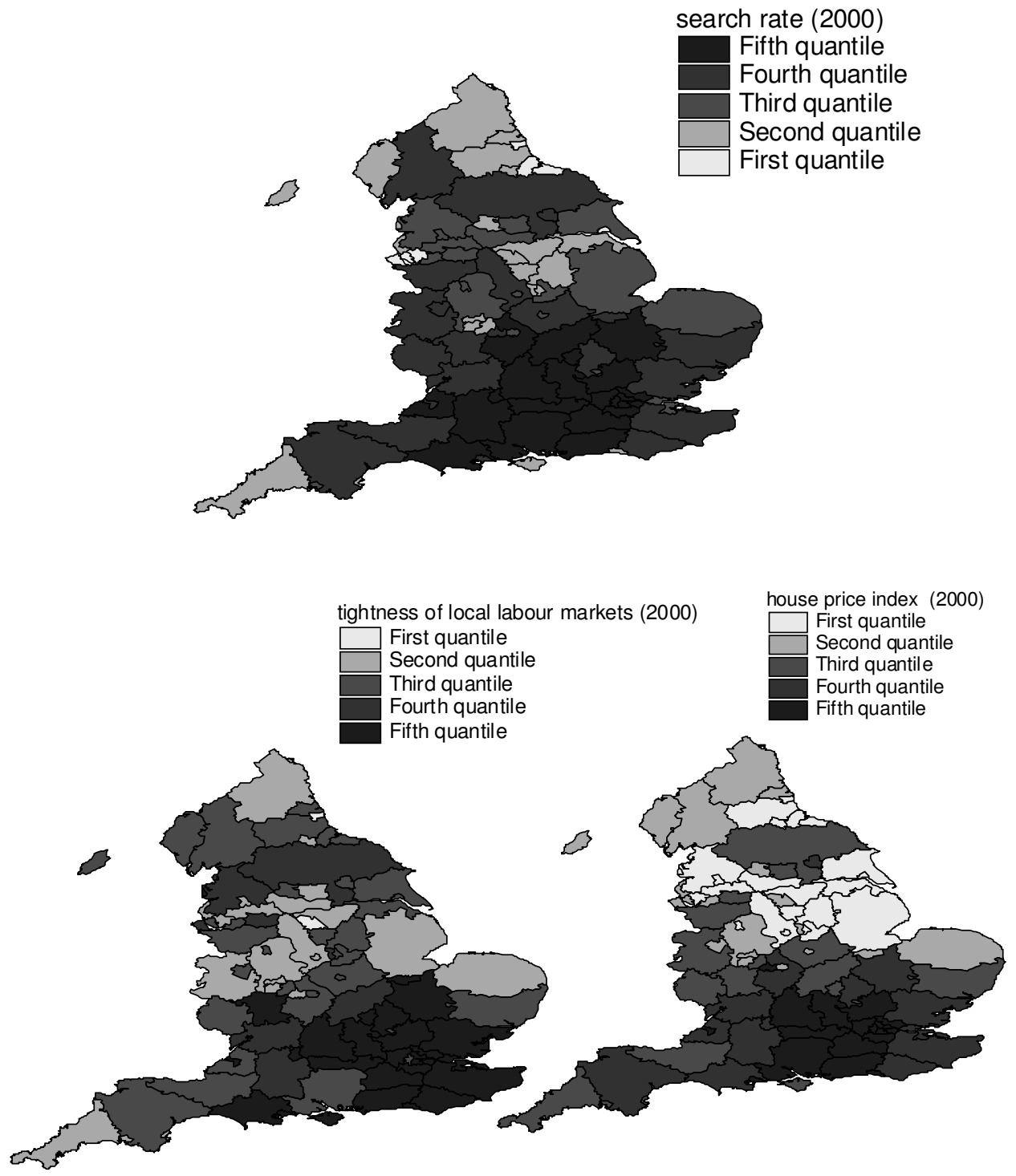

Figure 1: Quantile maps for Britain 


\section{Appendix 4: Dynamic panel data models with unobserved heterogeneity and systematic measurement errors}

Consistent estimators for a first order autoregressive panel data model with unobserved heterogeneity and measurement errors with an additive structure are presented. They are derived using a method of moments formulation.

The standard estimation of a dynamic panel model with exact measurement as proposed by Arellano and Bond (1991) is based on the assumption that errors are idiosyncratic shocks with cross-sectional zero mean at each point in time

$$
E\left(\varepsilon_{i t} \mid y_{i, t-1}\right)=0, \quad t=1, \ldots, T .
$$

However, this assumption can be inadequate in a number of cases. One circumstance, rather recurrent in real data, is the presence of time variant measurement errors common to all individuals. Consider a first order autoregressive panel data model with the same error structure as in model 1 (equation (11))

$$
\begin{aligned}
y_{i t}^{*} & =\alpha y_{i, t-1}^{*}+\eta_{i}+\varepsilon_{i t}, \quad|\alpha|<1, \quad i=1, \ldots, N ; t=2, \ldots, T, \\
y_{i t}^{*} & =y_{i t}+m_{i t}, \\
m_{i t} & =\phi_{t}+\mu_{i}+\xi_{i t}
\end{aligned}
$$

where $y_{i t}^{*}$ is the true underlying variable, $y_{i t}$ its observable counterpart and $m_{i t}$ is a measurement error with an additive structure defined as in model 1 (equation (11)). This error component structure is much more realistic if we consider measurement errors not only as observation errors in the narrow sense but also as discrepancies between theoretical variable definitions and their observable counterparts in a wider sense. The model in the observed variables is

$$
y_{i t}=\alpha y_{i, t-1}+\delta_{t}+d_{i}+e_{i t}
$$

where

$$
\begin{aligned}
\delta_{t} & =\alpha \phi_{t-1}-\phi_{t}, \\
d_{i} & =\alpha \mu_{i}-\mu_{i}+\eta_{i}, \\
e_{i t} & =\alpha \xi_{i, t-1}-\xi_{i t}+\varepsilon_{i t} .
\end{aligned}
$$


Our aim is to control for the effects of the errors on our observations. For this purpose, one can treat the $\delta_{t}$ as unknown period specific constants. If we define $v_{i t}$, the new composite disturbance component, as

$$
v_{i t}=\delta_{t}+e_{i t},
$$

then assumption (15) does not hold any longer and it is now replaced by

$$
E\left(v_{i t} \mid y_{i, t-1}\right)=\delta_{t}, \quad t=2, \ldots, T .
$$

Therefore, the estimators proposed by Arellano and Bond (1991) cannot be used. Furthermore, in this model, the estimators constructed by Biorn (2000) for panel data with measurement errors based on period means are also not valid. If the measurement errors have a period specific component, then the probability limit of period means taken when the number of individuals goes to infinity would no longer be zero. Thus, the estimators would not be consistent. Note also that equations (16)-(20) yields a constant autocorrelation of measurement errors independent of the lag

$$
\operatorname{Cov}\left(m_{i t}, m_{i, t-j}\right)=\sigma_{\mu}^{2},
$$

which is inconsistent with the basic assumption of the classical errors-invariables model, i.e. the measurement error are uncorrelated with everything else in the model included its own past values. However, following the GMM approach, consistent estimators can be derived using appropriate instruments.

The assumptions of equation (16) induce $M A(1)$ disturbances in the model involving observed variables (formulation (19)):

$$
\begin{aligned}
E\left(e_{i t} e_{i, t-s}\right) & =E\left[\left(\alpha \xi_{i, t-1}-\xi_{i t}+\varepsilon_{i t}\right)\left(\alpha \xi_{i, t-s-1}-\xi_{i, t-s}+\varepsilon_{i, t-s}\right)\right] \\
& =\left\{\begin{array}{cll}
-\alpha \sigma_{\xi}^{2} & \text { if } \quad s=1 \\
0 & \text { if } \quad s \geqslant 2 .
\end{array}\right.
\end{aligned}
$$

Therefore, once model defined by equation (19) has been transformed in first differences in order to purge the model from individual effects invariant over time

$$
\Delta y_{i t}=\alpha \Delta y_{i, t-1}+\Delta \delta_{t}+\Delta e_{i t}
$$

valid instruments are only obtained by using dependent variables that are at least three-times periods lagged. Consequently, the set of all appropriate moment conditions can be written as:

$$
\left\{\begin{array}{l}
E\left[y_{i, t-j}\left(\Delta y_{i t}-\alpha \Delta y_{i, t-1}\right)\right]=0 \\
E\left[\Delta \varepsilon_{i t}\right]=0
\end{array} j=3, \ldots,(t-1) ; t=3, \ldots, T,\right.
$$


where the second set of moments, always valid, might be used when a limited number of points in time is available. In fact the minimum number of time observation needed to get consistent estimators for a model in presence of measurement errors is greater that the one required when exact measurement is assumed. For instance, for a model like (16), we need to have at least four time observations. With $T=4, \alpha$ and $\Delta \delta_{3}$ are just identified from the two moment conditions

$$
\left\{\begin{array}{l}
E\left[y_{i 1}\left(\Delta y_{i 4}-\alpha \Delta y_{i 3}-\Delta \delta_{4}\right)\right]=0 \\
E\left[\Delta y_{i 4}-\alpha \Delta y_{i 3}-\Delta \delta_{4}\right]=0
\end{array} .\right.
$$

If $T>4$, and thus we have overidentifying restrictions, we can use the $G M M$ criterion. Calculate the sample equivalent of the moment conditions

$$
b_{T N}=\frac{1}{N} \sum_{i=1}^{N}\left[\begin{array}{c}
1 \\
y_{i, t-j}
\end{array}\right]\left(\Delta e_{i t}\right) \quad t=3, \ldots, T
$$

and minimize the quadratic form

$$
b_{T N}^{\prime} A_{N} b_{T N}
$$

where an optimal choice of weighting matrix $A_{N}$ is provided by the inverse of the variance of the orthogonality conditions and can be consistently estimated using the inverse of the variance of the sample moments conditions, $\widehat{A}_{N}$. The consistent GMM estimator, which has the smallest asymptotic covariance matrix for a GMM estimator based on the conditions (22), is ${ }^{12}$

$$
\widehat{\vartheta}=\underset{\vartheta}{\arg \min }\left(b_{T N}^{\prime} \widehat{A}_{N} b_{T N}\right) \text {. }
$$

However, such procedure does not use the information contained in the levels of the variables. It loses what is sometimes a very substantial part of the total variation in the data. Arellano and Bover (1995) and Blundell and Bond (1998) consider a first order panel data model as in equation (16) without measurement errors in variables and propose to combine the set of basic moment conditions relating to the equations in first differences with a set of moment conditions relating to the equations in levels. If there are instruments available that are not correlated with the individual effects, additional orthogonality conditions can be used. The efficiency of the resulting combined GMM

\footnotetext{
${ }^{12}$ See Hansen (1982) for details on the procedure in a time series context and, among others, Arellano and Bond (1991) for details on the application of the GMM to panel data models.
} 
estimator, the so called System GMM, is improved. Typically, first difference values of the variables dated $(t-1)$ are the candidate instruments. However, if measurement errors structured as in (17)-(18) are incorporated into the model, the serial correlation in the error term induces an endogeneity problem which makes one-time period lagged first differences of the variables invalid instruments

$$
E\left[\Delta y_{i, t-1} e_{i t}\right] \neq 0 \quad t=2, \ldots, T
$$

because $E\left(e_{i t} e_{i, t-1}\right) \neq 0$ as it is shown in (21). Therefore, a consistent System GMM estimator for model defined by (16) does not use a standard matrix of instruments but takes as instruments for the equations in levels first difference values of the variables dated $(t-2)$. Following Arellano and Bond (1991) and Arellano and Bover (1995) define the orthogonality conditions as

$$
E\left(Z_{i}^{+} H \varepsilon_{i}\right)=0,
$$

where

$$
H=\left(\begin{array}{c}
D \\
I
\end{array}\right) \text { is the transformation matrix }
$$

and

$$
Z_{i}^{+}=\left(\begin{array}{cc}
Z_{i}^{\prime} & 0 \\
0 & Z_{l i}^{\prime}
\end{array}\right) \text { is the matrix of instruments. }
$$

$D$ is the matrix that transform the variables in differences, $I$ is the identity matrix, $Z_{i}$ is the block diagonal matrix which contains the instruments available for the equations transformed by $H$, which is the same used in the standard estimation, and $Z_{l i}$ is also a block diagonal matrix which contains the instruments available for the equations in levels. For the model defined by (16) the matrices of instruments take the forms

$$
\underset{(T-2) \times m}{Z_{i}}=\left[\begin{array}{llllllll}
y_{i 1} & 0 & 0 & \cdots & 0 & 0 & \cdots & 0 \\
0 & y_{i 1} & y_{i 2} & \cdots & 0 & 0 & \cdots & 0 \\
\cdot & \cdot & \cdot & & . & . & & . \\
\cdot & \cdot & \cdot & & \cdot & \cdot & & \cdot \\
0 & 0 & 0 & \cdots & y_{i 1} & y_{i 2} & \cdots & y_{i(T-3)}
\end{array}\right] .
$$

where $m=\frac{(T-3) \times(T-2)}{2}$,

$$
\underset{(T-3) \times m}{Z_{l i}}=\left[\begin{array}{llllll}
\Delta y_{i 2} & 0 & 0 & . & 0 & 0 \\
0 & \Delta y_{i 4} & 0 & . & . & \vdots \\
. & . & . & . & . & . \\
0 & \ldots & . & . & 0 & \Delta y_{i(T-2)}
\end{array}\right] .
$$

where $m=\frac{2(T-3)}{2}=(T-3)$. 
Table 2. Estimation Results $(N=45, T=10)$

Dependent variable: Local search rate, $s$, at time $t$

\begin{tabular}{|c|c|c|c|c|}
\hline & $\begin{array}{c}\text { GMM-DIF }^{\diamond} \\
\text { (model 1) }\end{array}$ & $\begin{array}{c}\text { GMM-SYS }^{\diamond} \\
(\text { model } 1)\end{array}$ & $\begin{array}{c}\text { GMM-DIF }^{\bullet} \\
(\text { model } 2)\end{array}$ & $\begin{array}{c}\text { GMM-SYS } \\
(\text { model } 2)\end{array}$ \\
\hline$s_{t-1}$ & $\begin{array}{c}-0.2625^{* *} \\
(0.1221)\end{array}$ & $\begin{array}{c}-0.2136^{* * *} \\
(0.0649)\end{array}$ & $\begin{array}{l}0.1404^{* *} \\
(0.0621)\end{array}$ & $\begin{array}{c}0.1674^{* * *} \\
(0.0528)\end{array}$ \\
\hline $\bar{s}$ & $\begin{array}{l}0.5932^{* *} \\
(0.2864)\end{array}$ & $\begin{array}{c}0.6287^{* * *} \\
(0.2291)\end{array}$ & $\begin{array}{c}0.4234^{* * *} \\
(0.1567)\end{array}$ & $\begin{array}{c}0.4542^{* * *} \\
(0.1232)\end{array}$ \\
\hline$\theta$ & $\begin{array}{l}0.1999^{* * *} \\
(0.0751)\end{array}$ & $\begin{array}{c}0.2342^{* * *} \\
(0.0557)\end{array}$ & $\begin{array}{c}0.0224 \\
(0.0780)\end{array}$ & $\begin{array}{c}0.0698 \\
(0.0552)\end{array}$ \\
\hline $\bar{\theta}$ & - & - & $\begin{array}{l}0.2841^{* *} \\
(0.1235)\end{array}$ & $\begin{array}{c}0.3146^{* * *} \\
(0.1101)\end{array}$ \\
\hline$h$ & $\begin{array}{l}0.1356^{* *} \\
(0.0671)\end{array}$ & $\begin{array}{c}0.1510^{* * *} \\
(0.0459)\end{array}$ & $\begin{array}{c}0.0686 \\
(0.1998)\end{array}$ & $\begin{array}{c}0.0026 \\
(0.0724)\end{array}$ \\
\hline $\bar{h}$ & - & - & $\begin{array}{l}0.2011^{* *} \\
(0.0987)\end{array}$ & $\begin{array}{c}0.2292^{* * *} \\
(0.0653)\end{array}$ \\
\hline$d$ & $\begin{array}{l}-0.0140 \\
(0.0091) \\
\end{array}$ & $\begin{array}{l}-0.0125 \\
(0.0083) \\
\end{array}$ & $\begin{array}{l}-0.1207 \\
(0.1005) \\
\end{array}$ & $\begin{array}{l}-0.0645 \\
(0.0865) \\
\end{array}$ \\
\hline $\operatorname{AR}(1)$ & -3.299 & -3.926 & -3.594 & -4.033 \\
\hline $\operatorname{AR}(2)$ & -1.310 & 0.3586 & 1.302 & 0.401 \\
\hline $\begin{array}{c}\text { Sargan } \\
\text { (df) }\end{array}$ & $\begin{array}{l}26.52 \\
(118) \\
\end{array}$ & $\begin{array}{l}33.03 \\
(147) \\
\end{array}$ & $\begin{array}{l}15.18 \\
(182)\end{array}$ & $\begin{array}{l}18.14 \\
(226) \\
\end{array}$ \\
\hline
\end{tabular}

1. Year dummies are included in all specifications.

2. Asymptotic standard errors, using the small sample Windelmejer (2000) correction, are reported in parentheses.

3. ${ }^{*}$ Significant at $10 \%$ level; ${ }^{* *}$ Significant at $5 \%$ level; ${ }^{* * *}$ Significant at $1 \%$ level.

4. Instruments used in each equation:

$\diamond: s_{i, t-3}, s_{i(t-4)}, \ldots s_{i 1} ; \bar{s}_{i, t-3}, \bar{s}_{i(t-4)}, \ldots \bar{s}_{i 1} ; h_{i, t-3}, h_{i(t-4)}, \ldots h_{i 1} ; \theta_{i, t-2}, \theta_{i, t-3}, \ldots \theta_{i 1}$.

$\infty: s_{i, t-3}, s_{i(t-4)}, \ldots s_{i 1} ; \bar{s}_{i, t-3}, \bar{s}_{i(t-4)}, \ldots \bar{s}_{i 1} ; h_{i, t-3}, h_{i(t-4)}, \ldots h_{i 1} ; \theta_{i, t-2}, \theta_{i, t-3}, \ldots \theta_{i 1}$;

$\Delta s_{i, t-2} ; \Delta \bar{s}_{i, t-2} ; \Delta h_{i, t-2} ; \Delta \theta_{i, t-1}$.

- $: s_{i, t-3}, s_{i(t-4)}, \ldots s_{i 1} ; \bar{s}_{i, t-3}, \bar{s}_{i(t-4)}, \ldots \bar{s}_{i 1} ; h_{i, t-3}, h_{i(t-4)}, \ldots h_{i 1} ; \bar{h}_{i, t-3}, \bar{h}_{i(t-4)}, \ldots \bar{h}_{i 1}$; $\theta_{i, t-2}, \theta_{i, t-3}, \ldots \theta_{i 1} ; \bar{\theta}_{i, t-2}, \bar{\theta}_{i, t-3}, \ldots \bar{\theta}_{i 1}$.

•• $: s_{i, t-3}, s_{i(t-4)}, \ldots s_{i 1} ; \bar{s}_{i, t-3}, \bar{s}_{i(t-4)}, \ldots \bar{s}_{i 1} ; h_{i, t-3}, h_{i(t-4)}, \ldots h_{i 1} ; \theta_{i, t-2}, \theta_{i, t-3}, \ldots \theta_{i 1} ; \Delta s_{i, t-2}$; $\Delta \bar{s}_{i, t-2} ; \Delta h_{i, t-2} ; \Delta \bar{h}_{i, t-2} ; \Delta \theta_{i, t-1} ; \Delta \bar{\theta}_{i, t-1}$. 


\section{IZA Discussion Papers}

\begin{tabular}{|c|c|c|c|c|}
\hline No. & Author(s) & Title & Area & Date \\
\hline 757 & J. Hunt & Teen Births Keep American Crime High & 5 & $04 / 03$ \\
\hline 758 & $\begin{array}{l}\text { J. Lise } \\
\text { S. Seitz } \\
\text { J. Smith }\end{array}$ & $\begin{array}{l}\text { Equilibrium Policy Experiments and the } \\
\text { Evaluation of Social Programs }\end{array}$ & 6 & $04 / 03$ \\
\hline 759 & E. P. Lazear & The Peter Principle: A Theory of Decline & 1 & $04 / 03$ \\
\hline 760 & E. P. Lazear & Entrepreneurship & 5 & $04 / 03$ \\
\hline 761 & E. P. Lazear & $\begin{array}{l}\text { Output-Based Pay: Incentives, Retention or } \\
\text { Sorting? }\end{array}$ & 5 & $04 / 03$ \\
\hline 762 & $\begin{array}{l}\text { M. Gerfin } \\
\text { R. E. Leu }\end{array}$ & $\begin{array}{l}\text { The Impact of In-Work Benefits on Poverty and } \\
\text { Household Labour Supply - A Simulation Study } \\
\text { for Switzerland }\end{array}$ & 3 & $04 / 03$ \\
\hline 763 & $\begin{array}{l}\text { M. Biewen } \\
\text { S. P. Jenkins }\end{array}$ & $\begin{array}{l}\text { Estimation of Generalized Entropy and Atkinson } \\
\text { Inequality Indices from Complex Survey Data }\end{array}$ & 5 & $04 / 03$ \\
\hline 764 & P. A. Puhani & $\begin{array}{l}\text { A Test of the 'Krugman Hypothesis' for the } \\
\text { United States, Britain, and Western Germany }\end{array}$ & 2 & $04 / 03$ \\
\hline 765 & W. Schnedler & $\begin{array}{l}\text { On the Prudence of Rewarding A While Hoping } \\
\text { for B }\end{array}$ & 5 & $04 / 03$ \\
\hline 766 & $\begin{array}{l}\text { D. N. F. Bell } \\
\text { R. A. Hart }\end{array}$ & $\begin{array}{l}\text { How Important Is Guaranteed or Institutionalised } \\
\text { Overtime? }\end{array}$ & 5 & $04 / 03$ \\
\hline 767 & $\begin{array}{l}\text { P. Carneiro } \\
\text { K. T. Hansen } \\
\text { J. J. Heckman }\end{array}$ & $\begin{array}{l}\text { Estimating Distributions of Treatment Effects } \\
\text { with an Application to the Returns to Schooling } \\
\text { and Measurement of the Effects of Uncertainty } \\
\text { on College Choice }\end{array}$ & 6 & $04 / 03$ \\
\hline 768 & $\begin{array}{l}\text { J. J. Heckman } \\
\text { S. Navarro-Lozano }\end{array}$ & $\begin{array}{l}\text { Using Matching, Instrumental Variables and } \\
\text { Control Functions to Estimate Economic Choice } \\
\text { Models }\end{array}$ & 6 & $04 / 03$ \\
\hline 769 & $\begin{array}{l}\text { L. Flood } \\
\text { J. Hansen } \\
\text { R. Wahlberg }\end{array}$ & $\begin{array}{l}\text { Household Labor Supply and Welfare } \\
\text { Participation in Sweden }\end{array}$ & 3 & $04 / 03$ \\
\hline 770 & A. Heitmueller & Coordination Failures in Network Migration & 1 & $04 / 03$ \\
\hline 771 & $\begin{array}{l}\text { A. Calvó-Armengol } \\
\text { Y. Zenou }\end{array}$ & $\begin{array}{l}\text { Job Matching, Social Network and } \\
\text { Word-of-Mouth Communication }\end{array}$ & 5 & $05 / 03$ \\
\hline 772 & $\begin{array}{l}\text { E. Patacchini } \\
\text { Y. Zenou }\end{array}$ & $\begin{array}{l}\text { Search Intensity, Cost of Living and Local } \\
\text { Labor Markets in Britain }\end{array}$ & 3 & $05 / 03$ \\
\hline
\end{tabular}

An updated list of IZA Discussion Papers is available on the center's homepage www.iza.org. 